\title{
Atividade da amilase em rã-touro durante a fase pós-metamórfica
}

\author{
Luís Gustavo Tavares Braga( ${ }^{(1)}$, Maria Goreti de Almeida Oliveira(2), William Cardoso Lima ${ }^{(3)}$ \\ e Ricardo Frederico Euclydes ${ }^{(4)}$
}

\begin{abstract}
(1)Universidade Estadual de Santa Cruz, Dep. de Ciências Agrárias e Ambientais, CEP 45650-000 Ilhéus, BA. E-mail: gbraga@uesc.br (2)Universidade Federal de Viçosa (UFV), Dep. de Bioquímica e Biologia Molecular, CEP 36570-000 Viçosa, MG. E-mail: malmeida@ufv.br (3)UFV, Dep. de Química. E-mail: wclimax@terra.com.br (4)UFV, Dep. de Zootecnia. E-mail: rbaja@ufv.br
\end{abstract}

Resumo - O objetivo deste trabalho foi avaliar a atividade da amilase no quimo da rã-touro, Rana catesbeiana Shaw 1802 (3,6 a 200 g). Oitenta e sete animais foram distribuídos em baias-testes com temperatura e fotoperíodo controlados. As rãs selecionadas na fase pós-metamórfica receberam ração comercial extrusada ad libitum. Durante 87 dias de experimento, foram efetuadas 29 coletas em intervalos de 1 a 8 dias. As coletas do conteúdo intestinal foram feitas mediante a insensibilização das rãs em gelo e água e isolamento posterior do intestino delgado das mesmas. Para os testes da atividade da amilase, foram utilizados kits enzimáticos comerciais. A atividade da amilase foi observada a partir do terceiro dia e apresentou aumento até alcançar estabilidade, quando os animais pesavam 4,35 g. Do sétimo dia até o final do experimento, ocorreu a manutenção da estabilidade da atividade (137,44 UI) e atividade específica da amilase (14.688 UI mg-1).

Termos para indexação: Rana catesbeiana, atividade enzimática, enzimas digestivas, ranicultura.

\section{Amylase activity in the bullfrog during the post-metamorphic phase}

\begin{abstract}
The objective of this work was to evaluate the amylase activity in the chime of the bullfrog Rana catesbeiana Shaw 1802 (3.6 to 200 g). Eighty-seven animals were distributed in test stalls with controlled temperature and photoperiod. The frogs selected in the post-metamorphic phase received commercial extruded diet ad libitum. During 87 days of the experiment, 29 samples were collected in intervals varying from one to eight days. The intestinal content samples were made by first desensitizing of the frogs in ice and water, and subsequently removing the small intestine. For the tests of amylase activity, commercial enzymatic kits were used. Amylase activity was observed since the third day and it increased until reaching stability, when the animals weighed $4.35 \mathrm{~g}$. Amylase activity (137.44 UI) and specific activity (14,688 $\mathrm{UI} \mathrm{mg}^{-1}$ ) remained stable from the seventh day until the end of the experiment.
\end{abstract}

Index terms: Rana catesbeiana, activity enzymatic, digestive enzymes, frogculture.

\section{Introdução}

Apesar da boa infra-estrutura disponível nos ranários, os produtores se deparam com vários obstáculos. O principal é o preço elevado da produção, e a ração é o item de maior custeio. Além disso, os ranicultores enfrentam problemas com a baixa produtividade, causada por instalações deficientes, manejo inadequado e sanidade dos animais (Lima et al., 2004).

Para definir a formulação de rações compatíveis com as exigências nutricionais das rãs, nas diferentes fases de desenvolvimento, é preciso conhecer a fisiologia da digestão do animal. A eficiência de utilização dos alimentos está diretamente relacionada ao processo digestivo, no qual as enzimas têm papel fundamental.
Neves (1996) detectou a presença precoce de proteases não-específicas no periblasto de larvas de trairão (Hoplias cf. lacerdae) e pacamã (Lophiosilurus alexandri). No estômago, a atividade ocorreu principalmente na região glandular, mas foi sempre menos intensa do que nos intestinos das duas espécies.

A composição da dieta pode influenciar a liberação e atividade das enzimas digestivas. Onishi et al. (1976) relataram mudanças nos níveis de protease e amilase em carpa, após alimentação, comparando a freqüência de administração do alimento. Os autores relataram, ainda, que a atividade da amilase acompanhou esse período, tendo havido, contudo, decréscimo temporário após cada alimentação. Reimer (1982), ao estudar a adaptação das atividades das enzimas digestivas de Brycon 
melanoptorus, concluiu que a atividade da lipase pode ser aumentada com dietas ricas em carboidratos. Tal resultado foi corroborado por Cahu \& ZamboninoInfante (1994), que verificaram aumento da atividade da amilase em larvas de "sea bass" (Dicentrarchus labrax) alimentadas com dietas com 12\% de amido, em relação às larvas que receberam alimento vivo.

O efeito da dieta na atividade das enzimas digestivas também foi encontrado em larvas de D. labrax, em um experimento executado por Cahu et al. (1998), que sugeriram a presença de algas vivas na alimentação, como ponto-chave para o início das funções hidrolíticas das enzimas, assim como para o desenvolvimento das membranas, na borda em escova do intestino delgado.

Spannhof \& Plantikow (1983) trabalharam com truta arco-íris e observaram que a inclusão de produtos como amido solúvel na dieta, aumentou o volume dos sucos intestinais e o nível de açúcar no sangue, assim como induziu a um aumento prolongado na atividade da amilase nos sucos intestinais.

Segundo Seixas Filho et al. (1999), a diferença observada na atividade específica da amilase pancreática do piracanjuba (Brycon orbignyanus) e piau (Leporinus friderici) pode ter ocorrido em virtude da morfometria e do complexo arranjo de pregas da mucosa dos intestinos médio e posterior. Além disso, os autores concluíram que a atividade da amilase do surubim (Pseudoplatystoma coruscans) indicou a possibilidade de uso de ração que contém carboidratos.

Informações a respeito da atividade enzimática em anfíbios são escassas na literatura. Stéfani et al. (2002), ao trabalharem com rações isoprotéicas (30\% PB) e isoenergéticas ( $4.300 \mathrm{kcal} \mathrm{kg}^{-1}$ ) com porcentagens crescentes de inclusão de carboidratos (35\%, 40\% e 45\%), concluíram que a rã-touro (Rana catesbeiana) utiliza o carboidrato como fonte energética, o que demonstra a atividade da amilase desse animal na fase pósmetamórfica.

O objetivo deste trabalho foi avaliar a atividade enzimática da amilase no quimo da rã-touro (Rana catesbeiana Shaw, 1802) com pesos entre 3,6 g e 200 g.

\section{Material e Métodos}

Foram utilizados 87 exemplares de rã-touro (Rana catesbeiana Shaw, 1802) (Amphibia, Anura, Ranidae), provenientes do setor de recria do ranário experimental do Dep. de Biologia Animal, da Universidade Federal de Viçosa (UFV), no período de fevereiro a abril de 2001.
Os animais foram selecionados quando girinos, transcorrida toda a rotina de alimentação, triagem dos animais e troca de água ao longo dessa fase. As instalações e o manejo utilizados seguiram aqueles relatados por Lima \& Agostinho (1992) para o sistema anfigranja.

Ao término do processo de metamorfose, quando os imagos estavam aptos para serem transferidos para o setor de recria, foi efetuada a última triagem para uniformização do peso do lote. Posteriormente, os animais com peso médio de 3,6 g foram alojados em quatro baiastestes de $1,1 \mathrm{~m}^{2}$ suspensas, localizadas em salas com temperatura ambiente controlada $\left(27 \pm 1^{\circ} \mathrm{C}\right)$ e fotoperíodo de 12 horas. Para garantir maior conforto aos animais, foi colocado na parte seca do piso, área entre os cochos e a piscina, um tecido de algodão, umedecido diariamente. Esse procedimento foi realizado somente durante as duas primeiras semanas do experimento, quando os animais estavam mais suscetíveis à perda de umidade pelo contato com superfícies secas.

Utilizou-se uma ração comercial extrusada, com 42\% de proteína bruta e $4.533 \mathrm{kcal} \mathrm{kg}^{-1}$ de energia bruta. A ração era fornecida ad libitum nos cochos, juntamente com larvas de moscas (Musca domestica), para estimular e condicionar as rãs ao consumo de alimento. Inicialmente, a quantidade de larvas oferecida foi de $30 \%$ do peso da ração, reduzida gradativamente durante um período 30 dias até alcançar um valor de 5\%. As trocas de alimento e água foram feitas diariamente, pela manhã, e semanalmente era efetuada uma limpeza mais criteriosa com água e vassoura.

Para execução das análises de atividade enzimática da amilase, três rãs foram amostradas aleatoriamente das baias-testes, em intervalos previamente estabelecidos, de modo a obter-se grupos de animais em diferentes faixas de peso, ao longo de 87 dias de experimento.

Nos primeiros dez dias, as coletas do conteúdo do intestino delgado foram realizadas diariamente e, durante o restante do período experimental (77 dias), foram realizadas mais 19 coletas, em intervalos crescentes. Destas, cinco foram realizadas a cada intervalo de dois, três e quatro dias, e as quatro últimas, com intervalos de oito dias. A última coleta correspondeu ao dia em que foi coletada a primeira rã com peso superior a $200 \mathrm{~g}$, que corresponde ao peso comercial adotado pelos ranicultores.

Após a identificação, pesagem e insensibilização em água e gelo, as rãs sofreram incisão longitudinal ventral para exposição das vísceras e isolamento do tubo diges- 
tivo, e ligaduras duplas foram feitas nas porções cranial e caudal do intestino delgado, para evitar perdas do quimo a ser coletado e analisado. Em seguida, efetuou-se a extirpação do intestino delgado e, com o auxílio de pinça e tesoura, retirou-se todo conteúdo desse órgão, que foi empacotado em papel alumínio, identificado com data de coleta, peso do animal, número da repetição e tipo de órgão.

O condicionamento das rãs ao manejo alimentar permitiu a correta interpretação dos resultados de atividade enzimática, pois a presença de alimento no estômago, em quantidades similares, entre as rãs sacrificadas, assegurou proximidade do momento de alimentação e sincronia na secreção e atuação das enzimas. Para paralisar qualquer tipo de reação, após cada coleta, todo material devidamente embalado foi imerso em nitrogênio líquido e, posteriormente, armazenado à temperatura de $-40^{\circ} \mathrm{C}$. No laboratório, todas as amostras foram liofilizadas e mantidas em congelador, com temperatura de $-20^{\circ} \mathrm{C}$. As análises de atividade enzimática da amilase foram realizadas no Laboratório de Enzimologia, do Instituto de Biotecnologia Aplicada à Agropecuária (UFV).

Na preparação das amostras do quimo, $1 \mathrm{mg}$ do material liofilizado foi acondicionado em tubos de plástico e dissolvido em $0,5 \mathrm{~mL}$ de água destilada. Em seguida, a solução foi centrifugada a $35.000 \mathrm{~g}$, a $4^{\circ} \mathrm{C}$, por 20 minutos, e uma alíquota do sobrenadante foi retirada para a determinação da atividade enzimática da amilase.

A determinação da atividade baseia-se na hidrólise do amido pela amilase, com liberação de moléculas de glicose e dextrina. Pela adição de iodo, o amido não hidrolisado adquire coloração azul. A atividade da amilase é inversamente proporcional à intensidade de cor azul e calculada pela comparação com um controle de substrato. A leitura de cor desenvolvida é realizada em espectrofotômetro a 660 nm, comprimento de onda em que apresenta maior estabilidade (Caraway, 1959).

Para a preparação da amostra, foi retirado $1 \mathrm{mg}$ do material previamente liofilizado, que foi transferido para um tubo de plástico de $1 \mathrm{~mL}$ e, em seguida, adicionou-se $0,5 \mathrm{~mL}$ de água deionizada. Após a agitação por cinco minutos, a mistura foi centrifugada a $7.000 \mathrm{~g}$ por 10 minutos, para se proceder à análise da atividade.

A análise da atividade da amilase foi feita utilizando-se o kit enzimático da Bioclin, segundo a metodologia de Caraway (1959) modificada, conforme descrição a seguir. Em tubos previamente identificados (controle e teste), foram adicionados $250 \mu \mathrm{L}$ do reagente $\mathrm{n}^{\mathrm{0}} 1$. Em seguida, os tubos foram colocados em banho-maria a $37^{\circ} \mathrm{C}$, por dois minutos. Uma alíquota de $10 \mu \mathrm{L}$ do material a ser analisado foi colocada apenas no tubo-teste, agitado e, novamente, levado ao banho-maria a $37^{\circ} \mathrm{C}$, durante sete minutos e trinta segundos. Tal procedimento também foi feito com o tubo controle. Decorrido esse tempo, foram adicionados, a ambos os tubos, $250 \mu \mathrm{L}$ de reagente de trabalho e $2 \mathrm{~mL}$ de água deionizada. Após agitação, as absorbâncias dos tubos controle e teste foram determinadas a $660 \mathrm{~nm}$, em espectrofotômetro DU-70 Beckman. O aparelho foi zerado com água destilada e, para quantificar a atividade da amilase, foi utilizada a seguinte equação: Unidades da amilase $/ \mathrm{dL}=($ Abs (controle $)$ Abs(amostra))/Abs(controle).

Uma unidade da amilase representa a quantidade da enzima que hidrolisa, totalmente, $10 \mathrm{mg}$ de amido, em $30 \mathrm{~min}$, a $37^{\circ} \mathrm{C}$.

A concentração de proteína da amostra foi determinada utilizando-se a metodologia descrita por Warburg \& Christin (1941). O valor da atividade específica da amilase no quimo foi obtido, dividindo-se o valor da atividade pelo valor da concentração de proteína da respectiva amostra.

\section{Resultados e Discussão}

Nos dois primeiros dias de coleta, não foi verificada atividade da amilase no quimo da rã-touro, provavelmente devido à incapacidade da rã de secretar a enzima (Figura 1). O início do experimento coincidiu com o final da metamorfose, o que representa, entre outras

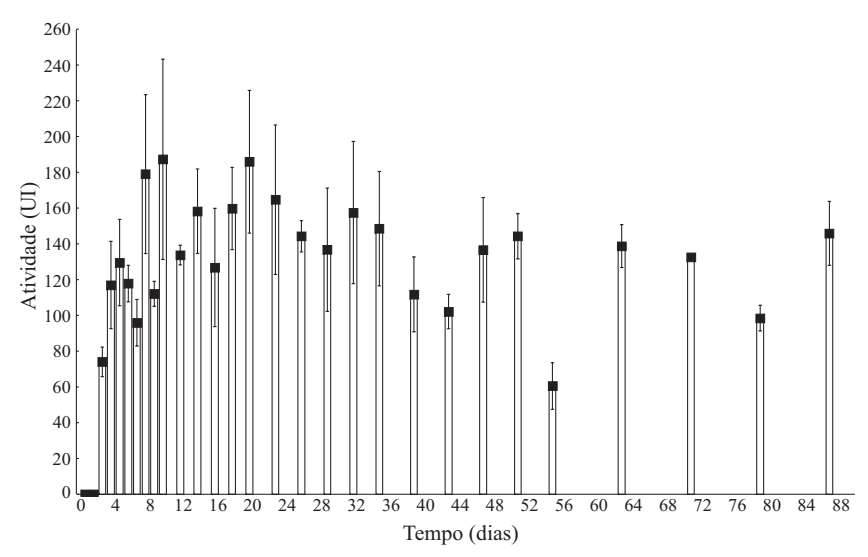

Figura 1. Perfil da atividade da amilase do quimo de rãstouro, alimentadas com ração comercial. 
mudanças anatômicas e fisiológicas ocorridas, o desenvolvimento do aparelho digestivo das rãs.

A atividade da amilase, na rã-touro, foi evidenciada a partir do terceiro dia de coleta do quimo, com valor de 74,02 UI. Houve aumento da atividade até o quinto dia, cujo valor foi igual a 129,54 UI, equivalente a $175 \%$ do observado no terceiro dia. A média encontrada, entre o quarto e o sexto dias (121,44 UI), foi próxima ao valor médio estabelecido entre o 70 e o 870 dias de experimento (137,44 UI), o que mostra que o aparato enzimático para secreção da amilase estava totalmente formado e a enzima em plena capacidade de hidrólise, quando as rãs, ainda consideradas imagos, atingiram peso médio de 4,35 g (Figura 2). Isto pode ser confirmado ao se analisar a atividade em todo o período experimental. Ou seja, durante as 29 coletas efetuadas, em apenas quatro oportunidades foram observados valores abaixo de 100 UI e, por sete vezes, foram encontrados valores de atividade superiores a $150 \mathrm{UI}$, que se concentraram entre o 8o e 32o dias de experimento.

Nas dez últimas coletas, realizadas do 35 dia, com as rãs pesando $44,12 \mathrm{~g}$, até o último dia, o valor médio da atividade da amilase no quimo foi de 122 UI. Essa informação confirma que as rãs estavam preparadas para digerir alimentos constituídos de amido, desde a fase inicial de imago, permanecendo a velocidade de atividade da amilase estável em todo período restante, até 0 animal atingir 179,1 g, com crescimento médio diário de 2,04 g. A capacidade da rã-touro, de digerir e utilizar carboidratos provenientes da dieta, já havia sido mencionada por Stéfani (2002), e demonstra um efeito economizador da proteína para obtenção de energia, que é destinada para o crescimento corporal. Tal fato pode ser confirmado nos trabalhos realizados por Braga et al. (1998) e Castro et al. (2001), que mediram os valores

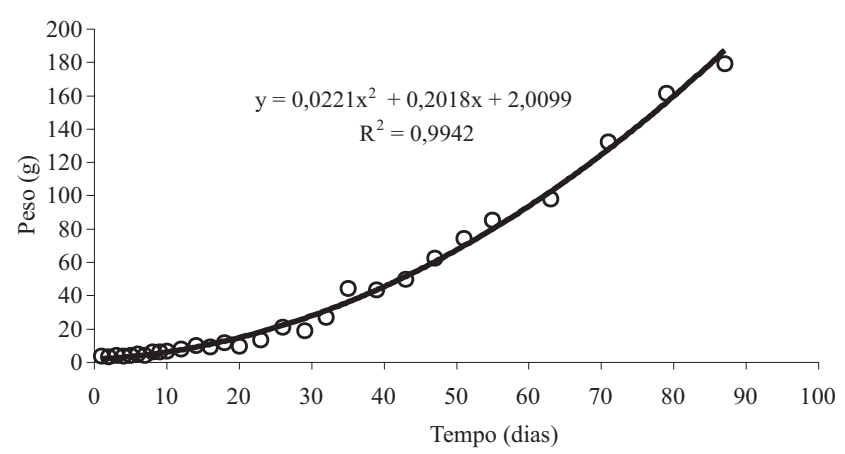

Figura 2. Ganho de peso de rãs-touro, alimentadas com ração comercial durante 87 dias de experimento. nutritivos de diversos alimentos de origem vegetal, para rãs com peso médio de $25 \mathrm{~g}$.

A atividade específica da amilase, coletada no quimo das rãs, apresentou duas fases de estabilidade distintas: a primeira está localizada entre o 2 o e 9o dias, com valor médio de $7.519 \mathrm{UI} \mathrm{mg}^{-1}$. Na outra fase, caracterizada por 20 coletas ocorridas durante 77 dias, registrou-se a média de 14.688 UI mg-1 ${ }^{-1}$ com aumento de $95 \%$ em relação à primeira fase (Figura 3). Esse comportamento reforça as informações obtidas com a atividade da amilase, que teve sua estabilidade evidenciada ainda na fase de imago.

Ao se analisar os dados da atividade da amilase, em função do peso das rãs, pode-se constatar diminuição nos valores desse parâmetro, à medida que as rãs ganharam peso, dos quais são destacados dois momentos com inclinações diferentes para essa redução (Figura 4).

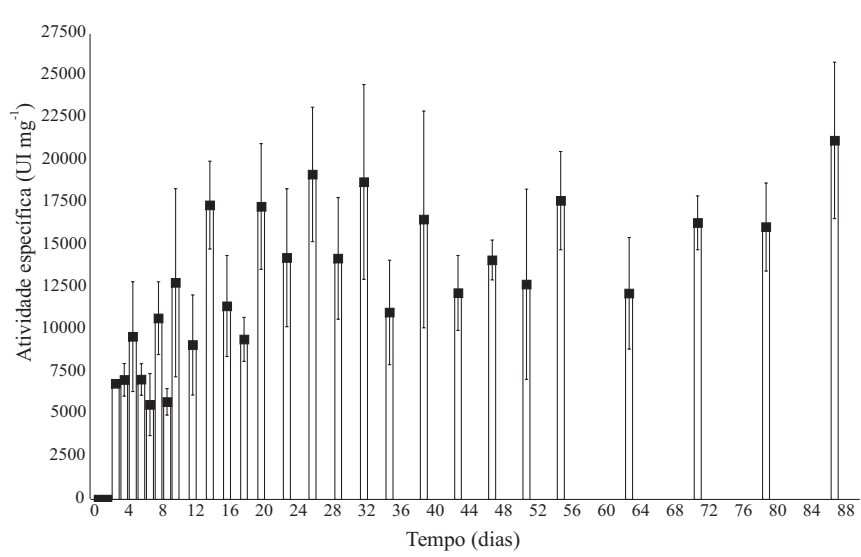

Figura 3. Perfil da atividade específica da amilase do quimo de rãs-touro, alimentadas com ração comercial.

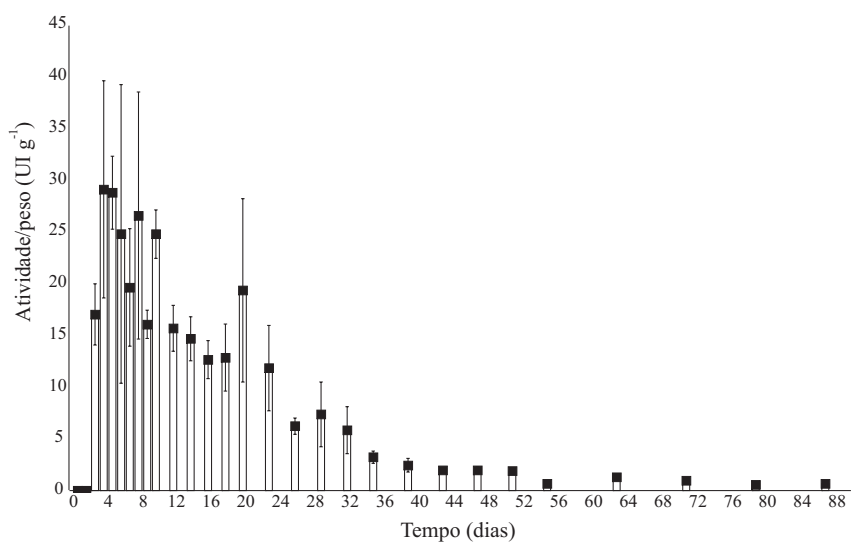

Figura 4. Perfil da atividade da amilase, em relação ao peso das rãs-touro, alimentadas com ração comercial. 
Na primeira etapa, correspondente a 19 coletas, feitas durante os primeiros 32 dias, a atividade da amilase, em função do peso das rãs, teve seu valor máximo $\left(29,12 \mathrm{UI} \mathrm{g}^{-1}\right)$ no quarto dia de experimento, em que as rãs pesaram 3,98 g, e, na seqüência, a taxa de redução diária foi de $0,83 \mathrm{UI} \mathrm{g}^{-1}$ até alcançar 5,84 UI g-1 . A segunda e última etapa de redução da atividade, em função do peso dos animais, aconteceu a partir do $35^{\circ}$ dia, com velocidade menor do que na primeira etapa. Nesse período de 52 dias, constatou-se diminuição de $0,05 \mathrm{UI} \mathrm{g}^{-1}$ por dia, até ser atingido o valor de $0,68 \mathrm{UI} \mathrm{g}^{-1}$, no 870 dia. Com isto, pôde-se verificar que no período em que as rãs tiveram maior crescimento, a velocidade da atividade dessa enzima permaneceu estável, o que demonstra que essa espécie possui a secreção de amilase já estabelecida na fase inicial de desenvolvimento, com o peso dos animais inferior a $45 \mathrm{~g}$.

\section{Conclusões}

1. A atividade da amilase alcança estabilidade ainda na fase de imago da rã-touro.

2. A rã-touro apresenta capacidade para digestão de alimentos de origem amilásica no período observado.

\section{Referências}

BRAGA, L.G.T.; LIMA, S.L.; DONZELE, J.L.; CASTRO, J.C. Valor nutritivo de alguns alimentos para rã-touro (Rana catesbeiana Shaw, 1802) na fase de recria. Revista da Sociedade Brasileira de Zootecnia, v.27, p.203-209, 1998.

CAHU, C.L.; ZAMBONINO-INFANTE, J.L. Early weaning of sea bass (Dicentrarchus labrax) larvae with a compound diet: effect on digestive enzymes. Compendium of Biochemistry and Physiology, v.109A, p.213-222, 1994.

CAHU, C.L.; ZAMBONINO-INFANTE, J.L.; PÉREZ, A.; QUAZUGUEL, P.; GALL, M.M. Algal addition in sea bass
(Dicentrarchus labrax) larvae rearing: effects on digestive enzymes. Aquaculture, v.161, p.479-489, 1998.

CARAWAY, W.T. A stable starch substrate for the determination of amylase in serum and other body fluids. American Journal of Clinical Pathology, v.32, p.97-99, 1959.

CASTRO, J.C.; SILVA, D.V.; SANTOS, R.B.; MONDENESI, V.F.; ALMEIDA, E.F. Valor nutritivo de alguns alimentos para rãs. Revista da Sociedade Brasileira de Zootecnia, v.30, p.605-610, 2001.

LIMA, S.L.; AGOSTINHO, C.A. A tecnologia de criação de rãs. Viçosa, MG: Universidade Federal de Viçosa, 1992. 168p.

LIMA, S.L.; AGOSTINHO, C.A.; MOURA, O.M. Ranicultura brasileira: novos caminhos? Panorama da Aqüicultura, v.14, p.37-41, 2004.

NEVES, C.A. Estudo morfológico e histoenzimológico do desenvolvimento ontogenético do trato digestivo de larvas e alevinos de trairão (Hoplias cf. lacerdae) e pacamã (Lophiosilurus alexandri). 1996. 574p. Dissertação (Mestrado) - Universidade Federal de Minas Gerais, Belo Horizonte.

ONISHI, T.; MURAYAMA, S.; TAKEUCHI, M. Changes in digestive enzyme levels in carp after feeding. III: Response of protease and amylase to twice-a-day feeding. Bulletin of Japanese Society of Scientific Fisheries, v.42, p.921-923, 1976.

REIMER, G. Studies on the enzymatic activities in the gastrointestinal of the Brycon melanoptorus. Journal of Fish Biology, v.21, p.637642, 1982.

SEIXAS FILHO, J.T.; OLIVEIRA, M.G.A.; DONZELE, J.L.; GOMIDE, A.T.M.; MENIN, E. Avaliação da atividade da amilase em quimo de três espécies tropicais de peixes Teleostei. Revista da Sociedade Brasileira de Zootecnia, v.28, p.907-913, 1999.

SPANNHOF, L.; PLANTIKOW, A. Studies on carbohydrate digestion in rainbow trout. Aquaculture, v.30, p.95-108, 1983.

STÉFANI, M.V.; NAKAGHI, L.S.O.; URBINATI, E.C. Alterações estruturais do fígado da rã-touro (Rana catesbeiana Shaw, 1802) submetida a deitas com níveis crescentes de carboidratos. Arquivos de Veterinária, v.18, p.78-82, 2002.

WARBURG, O.; CHRISTIN, W. Isohering und kristallisation des görungs ferments enolase. Biochemistry Zoology, v.310, p.384421, 1941. 